\title{
Engaging Organizations of Persons with Disabilities in Humanitarian Responses
}

\author{
Dale Buscher ${ }^{1,2}$ \\ 1 Senior Director for Programs, Women's Refugee Commission, New York, NY 10019, USA; \\ daleb@wrcommission.org; Tel.: +1-212-551-3129 \\ 2 School of International and Public Affairs, Columbia University, New York, NY 10027, USA
}

Received: 4 September 2018; Accepted: 30 October 2018; Published: 1 November 2018

\begin{abstract}
This project report captures 10 years of work by the Women's Refugee Commission on the inclusion of disability in humanitarian responses. The report covers early research on refugees with disabilities and subsequent work on disability inclusion, including the target areas of gender-based violence, child protection, and sexual and reproductive health. Later presented work focuses on engaging organizations of persons with disabilities (DPOs) in humanitarian responses-both as expert resources to inform humanitarian actors as well as sources of information, services, and social support for refugees with disabilities living in their host communities. The report concludes with recent work on soliciting input from DPO networks on the Guidelines on the Inclusion of Persons with Disabilities in Humanitarian Action, which are currently under development.
\end{abstract}

Keywords: disabilities; organizations of persons with disabilities (DPOs), refugees; inclusion; protection; humanitarian actors; humanitarian response

\section{Introduction}

Refugees with disabilities have historically been overlooked, neglected, and marginalized in humanitarian responses [1] (p. 1). The Women's Refugee Commission is a non-governmental organization for applied research and advocacy that works to improve humanitarian responses in situations of crises and conflict, in order to enhance the protection and well-being of displaced women, children, and youth. This project report documents a variety of initiatives undertaken over the past decade by the Women's Refugee Commission (WRC) to place refugees with disabilities higher on the international agenda. The WRC's efforts focused on ensuring that disabled refugees' needs were addressed, that their voices were heard, and that they were included in all humanitarian programs and services. The work was initiated with the UN Refugee Agency, the UN High Commissioner for Refugees (UNHCR), and its partner organizations, and was later expanded to bridge the gaps between humanitarian service providers and organizations of persons with disabilities (DPOs). Ultimately, this work is focused on influencing the broader humanitarian community through the World Humanitarian Summit and the resultant development of inter-agency guidelines on disability inclusion in humanitarian practice (currently under development).

\section{Methods Used by the WRC}

This report covers a decade of work, including numerous assessments, consultations, and provisions of technical assistance in multiple of countries with a myriad of $\mathrm{UN}$, international NGO, local NGO, and DPO partners. This section summarizes the methods used to inform WRC initiatives and their respective limitations. As such, different methods were employed for the different activities and assessments, including: 
(1) Review of existing UN, NGO, international, and national policies on disabilities, with a particular reference to displacement and disability. Literature reviews were conducted using Google Scholar as well as accessing international NGO, disability NGO, and research institute websites and UN databases. The following key words/phrases were used: refugees with disabilities, disabilities in humanitarian action/response, displaced women and girls with disabilities, and disability inclusion in humanitarian practice.

(2) Global desk research into conditions for displaced persons in different refugee and internally displaced person (IDP) contexts. This included a review of UNHCR country reports, policy documents, and systems (such as the ProGres registration system to assess how refugees were identified), as well as available public documents from UNHCR's implementing partners with respect to disability (such as Handicap International, Christian Blind Mission, HelpAge, and World Vision) to assess if and how disability inclusion was referenced and noted.

(3) Telephone and Skype interviews with key actors and experts, including relevant staff at the UNHCR's headquarters from the Division of International Protection: the Community-Based Protection Advisor, the Education Advisor, and the Child Protection Advisor. Selected staff from partner organizations, including headquarters-based staff at Handicap International, Christian Blind Mission, HelpAge, World Vision, Mercy Corps, and the International Rescue Committee, were also interviewed, as were the disability advisors from both the World Bank and the U.S. Agency for International Development.

(4) Field studies into the specific conditions for refugees with disabilities,

(5) Participatory assessments with refugees with disabilities.

(6) Direct observation of service provision for refugees with disabilities in multiple contexts.

The various field studies and assessments conducted were generally in response to requests from the field, that is, made by organizations that already understood the need for disability inclusion but struggled with operationalization. As such, the field assessment sites and partners supported may not be reflective of humanitarian response globally. Further, the refugees with disabilities who participated in group discussions and activities were those who voluntarily agreed to participate and gave verbal and/or written consent, as did their caregivers, when necessary. Thus, those with severe and/or multiple disabilities were often excluded.

The participatory self-assessment of DPOs was designed to support remote data collection from grassroots groups of women with disabilities in their local languages. Some women's DPO leaders, however, had limited in-person contact with members, which made it challenging for them to complete the activity as outlined. Others found the self-assessment tool too technical or challenging to understand. This resulted in a number of semi-complete sections in the assessments. The WRC also used existing DPO partnerships for the participatory self-assessment, which limited the scope of the findings to certain geographical regions, notably Africa and South Asia.

(7) Online surveys of both humanitarian practitioners and DPOs.

Online survey respondents were invited to participate through their affiliation with an existing network, such as membership in the Gender-Based Violence Area of Responsibility (GBV AoR, a global level forum for coordination of efforts related to preventing and addressing GBV in humanitarian contexts) or a DPO regional network, and/or their connection to the disability, humanitarian, and gender communities to share positive practices on inclusion of women and girls with disabilities. As such, most respondents already had some interest and/or experience in disability inclusion. The survey did not intend to reach nor be reflective of the views and experiences of the broader humanitarian community. The findings, therefore, may not reflect the range of challenges that less experienced humanitarian organizations and actors may face or perceive related to disability inclusion. Further, the survey findings are biased towards larger organizations and agencies with linkages to global communities of practice, those with access to the internet, and those able to read and write in English. 
(8) Training and workshops with both persons with disabilities as well as humanitarian practitioners.

Overall, the decade of work included field-based activities in: Nepal, the Philippines, India, Bangladesh, Thailand, Jordan, Lebanon, Iraq, Yemen, Uganda, Ethiopia, Burundi, and the Northern Caucasus in the Russian Federation. More than 2000 refugees and their care-givers were consulted over the many projects, as well as 200 experts and humanitarian practitioners. Other than the online surveys conducted, all research was qualitative and primarily used focus group discussions, participatory ranking exercises, and stories of most significant change methodologies. Tools and techniques employed were adapted to account for speech, hearing, and visual impairments. The WRC's internal research working group reviewed all research protocols and questionnaires.

The following sections summarize the salient findings of the above data collection efforts.

\section{Humanitarian Context}

There are over 68.5 million people displaced by conflict and violence [2]; this is the largest figure ever recorded [3]. The majority (85\%) are displaced in less developed countries [2], and they are displaced for longer periods of time-26 years, on average, for refugees [4] (p. 2). An estimated 15\% of these individuals are persons with disabilities [5], translating to approximately 10,275,000 people.

Historically, humanitarian response has viewed persons with disabilities as people with needs rather than as individuals with abilities, capacities, and contributions, resulting in a disparate response of specialized services, such as community-based rehabilitation (CBR) and the provision of mobility devices, rather than a focus on disability inclusion across all humanitarian programs and services [6] (p. 34). Ultimately, this has increased invisibility, isolation, and neglect, with few benefitting from educational resources, employment, sexual and reproductive health services, and community participation and leadership opportunities [1] (pp. 2-5).

While most are overlooked, those with physical impairments, due to their heightened visibility, often receive more targeted support than those with sensory impairments; those with intellectual impairments generally receive least [6] (p. 34). Humanitarian actors have been remiss at understanding and identifying the diversity that exists within the disability population [7] (p. 168), [8] p. 18); further, they often lack the requisite knowledge and skills for working with and including persons with disabilities in their assessments, programs, and staffing [8] (p. 18), [9] (pp. 17-20).

\section{Localization}

Disability expertise exists in almost every situation where humanitarian actors respond to emergencies and displacement. While this expertise rarely forms part of the work of mainstream service providers (for example, providers of health services and education, employers, and water and sanitation providers), local organizations of persons with disabilities (DPOs) are generally present (although almost never engaged) in humanitarian responses [10] (p. 2). There is a myriad of reasons for this: ignorance about the existence and expertise of DPOs, humanitarians' reluctance to work with and through the most local of civil society organizations, the severe funding challenges DPOs face, and the challenges in bringing non-humanitarian actors into humanitarian responses [10] (pp. 25-27).

Despite the rhetoric and push for localization in humanitarian programming, including at the World Humanitarian Summit [11], progress has been slow. Further, the discussion on localization has had a focus on partnering with national non-governmental organizations-generally those already engaged in the response, rather than local civil society groups who lack humanitarian experience. Drawing on locally available expertise, for example through DPOs and local LGBT groups, could help shape and inform responses, this, however, has never been a strength or a common practice of humanitarians [12] (pp. 25-30). When attempting to understand safety concerns, the rights' environment, advocacy with hosting governments, and the like for traditionally marginalized populations, who is better placed than local civil society groups such as DPOs and LGBT organizations to provide the context, experiences, and expertise? 


\section{Protection Concerns of Women and Girls with Disabilities}

The mapping activities undertaken by the WRC found the inclusion of women and girls with disabilities remains a gap in humanitarian response as well as a corresponding lack of leveraging of the expertise that organizations of women and girls with disabilities could bring to the response. Additional pieces of research carried out by the WRC found high levels of risks among refugee women and girls with disabilities $[1,8,12]$. The risks result, in part, from the marginalization and exclusion of women and girls with disabilities in programs and services that could strengthen their social and protective networks [1,12].

In 2008, WRC conducted cross-sectional research that examined the protection concerns and inclusion into services of persons with disabilities in humanitarian settings including field studies in Nepal, Thailand, and Ecuador-which found sexual violence, domestic abuse, and physical assault among the risks facing refugee women with disabilities [1] (p. 32). More recent assessments undertaken by WRC with refugees and displaced persons in Bangladesh, Ethiopia, India, Lebanon, Nepal, the Philippines, Thailand, and Uganda found violence was reported by both men and women with disabilities in all contexts [9] (pp. 11-13). These same assessments found that isolation, the lack of contact with community networks, and few independent living options exposed both men and women with disabilities to different forms of violence including inside the home [8] (p. 11).

From 2012-2014, WRC conducted a study into the sexual and reproductive health access, needs, risks, and capacities of refugees with disabilities in Kenya, Nepal, and Uganda. The field studies found that refugees with disabilities who are isolated in their homes, and those with intellectual disabilities, had reduced access to information about family planning, violence, and other sexual and reproductive health issues. Risks of sexual violence were highlighted across all three of the field study sites [13] (p. 4). In another project, WRC conducted participatory research with the International Rescue Committee on disability inclusion in GBV programming in Ethiopia, Burundi, Jordan, and the Northern Caucasus in the Russian Federation. The research found that women with physical disabilities who are isolated in their homes in urban settings were being raped on a repeated and regular basis, often involving multiple perpetrators; and that women, men, girls, and boys with intellectual disabilities were particularly vulnerable to all forms of sexual violence [9] (pp. 10-17).

Additional research carried out by WRC in Lebanon, Uganda, and India on the risks of gender-based violence in urban areas for marginalized refugee groups found that refugees with disabilities are stigmatized and discriminated against on the basis of their disability [12]. This discrimination is further exacerbated when their disability intersects with other social markers such as refugee status, nationality, ethnicity, religion, and gender. Further, the additional stigma associated with being raped makes many women and girls reluctant to report such violence. Their isolation and limited interactions with people outside their immediate family also add to reporting barriers [12] (p. 111). Other GBV risks identified included isolation, the loss of protective networks, discrimination in GBV service provision, and limited linkages with host country DPOs [12] (pp. 115-118).

\section{Linkages to Host Country DPOs}

Recognizing that organizations of persons with disabilities play a critical advocacy role in shaping government policy and programs, the Women's Refugee Commission (WRC) undertook a multi-year project to engage DPOs in humanitarian response. The efforts included training and capacity-building and the forging of links between DPOs and more traditional humanitarian actors. As the needs and capacities of women and girls with disabilities were most under-represented in gender, protection, and disability fora in humanitarian crises, the WRC focused specifically on supporting organizations and networks of women with disabilities with the aim of engaging them to advocate on humanitarian issues at local, national, regional, and global levels. The project, funded by the Australian government and UN Women, commenced with a mapping to identify and document the role of organizations of women with disabilities in humanitarian response, and effective strategies for the inclusion of 
women and girls with disabilities in humanitarian and post-conflict programs [10] (p. 8). This mapping included online surveys for select humanitarian practitioners and disability actors, a self-assessment exercise, and key informant interviews [10] (pp. 9-11).

While there is little in the peer-reviewed literature that specifically focuses on the inclusion of women and girls with disabilities in humanitarian action, there is a growing body of grey literature, reports, and assessments, as well as governmental policies, that recognizes that women and girls with disabilities face additional risks in humanitarian crises [8,9,14-20]. Yet, even though it is increasingly recognized that women and girls with disabilities are at heightened risks and continue to be overlooked and excluded, humanitarian actors fail to identify, engage, and include these populations. This is both a consequence of naivety, failing to even recognize this gap, as well as hesitancy and inexperience. Practitioners often believe that they don't know how to talk to or work with these populations and fail to recognize that expertise is available locally through host country DPOs [8,9]. A WRC report from 2008, however, found that refugee women and girls with disabilities were largely not connected with local DPOs and local DPOs were not informed or aware of the unique needs and vulnerabilities of displaced and refugee women and girls with disabilities living within their countries and communities [1] (p. 4).

In order to identify initiatives relating to disability, gender, and humanitarian action, including project resources, trainings, and positive programming practices, WRC undertook a number of activities referenced above: an online survey for humanitarian professionals ( 91 respondents), an online survey for disability actors including DPOs (35 survey respondents), key informant interviews representing a range of organizations across the disability and humanitarian sectors (roughly 24), and participatory self-assessments for women DPO leaders (9 organizations participated) [9] Findings from humanitarian professionals included acknowledgement of gaps in policy development and implementation, that is, policies and commitments on protection and empowerment of affected populations generally lack specific reference to women and girls with disabilities. Humanitarian professionals also noted the negative attitudes of family and community members who were often fearful or protective with regards to female family members with disabilities being included in their programs and services Additionally, staff knowledge, attitudes, and practices lead humanitarian actors to believe that they are ill-equipped to include women and girls with disabilities in their programs and services [10] (pp. 13-14).

Findings from organizations of women with disabilities identified strengths and potential contributions - such as playing critical roles in identifying the concerns of women and girls with disabilities in affected populations, assistance in mobilizing those populations, and bringing critical expertise to humanitarian organizations. The women's DPOs also identified a number of barriers and challenges to further engagement in humanitarian response. These included: funding challenges and resultant limited organizational capacity, perceptions of being excluded from both the disability and women's rights movements, and a lack of understanding of humanitarian issues, architecture, and processes [10] (pp. 20-27).

\section{Moving Forward}

In an attempt to address some of the concerns noted in engaging and supporting DPOs to play a role in humanitarian response, the WRC undertook four complementary activities: (1) supporting DPO pilot activities that included refugees; (2) facilitating training focused on strengthening the role of women with disabilities in humanitarian action; (3) bringing women with disabilities to global fora such as the Commission on the Status of Women in New York, the Association of Women in Development (AWID) conference in Brazil, and the World Humanitarian Summit in Istanbul; and (4) conducting workshops with regional DPO networks to solicit input on the Inter-Agency Standing Committee (IASC) guidelines being drafted on disability inclusion. Each of these activities is described in detail below: 
1. DPO Pilot Activities: One of the pilot activities undertaken provided funding support to the Lebanese Association for Self-Advocacy (LASA), an organization run by and for persons with intellectual disabilities. Throughout 2015-2016, LASA expanded their engagement with refugees with intellectual disabilities and facilitated 14 training and educational sessions on rights, decision-making, and safety with refugees with disabilities and their caregivers. The sessions, which brought together both Lebanese individuals and refugees with intellectual disabilities, helped create linkages and address the isolation and lack of peer and protective networks many refugees with disabilities face [21].

2. Training focused on strengthening the role of women with disabilities in humanitarian action: In an effort to strengthen the capacity of women with disabilities and DPOs to engage in humanitarian response and include refugees with disabilities in their advocacy efforts, programs, and services, WRC facilitated a number of workshops with DPOs in refugee hosting countries. Participating DPOs and DPO networks included: The Network of African Women with Disabilities, the South Asia Disability Forum, Women Challenged to Challenge (Kenya), the African Disability Alliance, and the Special Talent Exchange Program (Pakistan). The trainings aimed to enhance the capacity of women with disabilities to effectively advocate on women's and disability issues within relevant humanitarian fora at national and regional levels by: (1) increasing understanding of the humanitarian system; (2) helping participants identify gaps and opportunities for inclusion of women and girls with disabilities within the humanitarian system; and (3) developing advocacy plans to strengthen their inclusion. While just an initial step for tackling a longer-term issue, a facilitator's guide was produced to help continue and spread the efforts and learning [22].

3. Bringing women with disabilities to global for a: To further highlight the voices and capacities of women with disabilities, WRC sponsored a number of women to speak at high level global fora including the Commission on the Status of Women in New York, the World Humanitarian Summit in Istanbul, and the Association of Women in Development (AWID) conference in Bahia, Brazil. At each event, the women highlighted the critical role local organizations of women, including those with disabilities, can play in bridging the humanitarian/development divide, and representing the rights of refugee women and girls with humanitarian organizations, government departments, and in human rights mechanisms. Participation and speaking at these events sought to address the exclusion women and girls with disabilities face from both the disability and women's rights movements [23].

4. Workshops to solicit input on the Inter-Agency Standing Committee (IASC) guidelines: Finally, during the Spring and early summer of 2018, WRC facilitated two regional workshops to engage DPOs in the drafting of the U.N. Inter-Agency Standing Committee (IASC) Guidelines on the Inclusion of Persons with Disabilities in Humanitarian Action process. The IASC Guidelines are a direct follow up to the Disability Charter signed onto by 25 governments, $14 \mathrm{UN}$ agencies, and nearly a hundred international organizations, networks, and NGOs [24]. While not legally binding, the Guidelines will serve to inform humanitarian response and provide concrete instructions to humanitarian actors on expected practice. WRC is leading on the integration of gender and gender-based violence in the inclusion guidelines and the regional workshops, one in Addis Ababa, and one in Bangkok, focused on eliciting input from persons with disabilities on the integration of gender and the prevention and response to GBV throughout the guidelines. The objectives of the consultation workshops were to:

(1) Identify priority areas for gender mainstreaming and GBV prevention and response across the guidelines;

(2) Collect useful resources, promising practices and other relevant information for gender and GBV actors to be integrated into the Guidelines; and, 
(3) Map opportunities for gender and GBV actors in the regions to contribute to later phases of the Guidelines development and rollout process.

The workshops included representatives from DPOs and DPO networks, as well as Child Protection and GBV sub-cluster actors in the regions. Critical issues raised by participants included: emphasizing the positive potential of persons with disabilities, including positive examples of inclusion, highlighting intersecting identities, ensuring that persons with multiple disabilities are identified and included, fostering the participation and empowerment of women and girls with disabilities, and organizing meetings between GBV actors and organizations of women with disabilities to broaden partnerships for prevention and response to gender-based violence. Participants also emphasized the importance of ensuring that all actions relating to inclusion are based on the human rights model of disability and avoiding use of the medical model and that all actions are firmly aligned with the Convention on the Rights of Persons with Disabilities (CRPD) [25].

\section{Challenges}

While the WRC's support of DPO pilot activities as well as the facilitating of DPO trainings and workshops provided opportunities for DPOs to further engage in both humanitarian policy and practice, DPOs struggle with limited resources and stretched capacity. They frequently lack an understanding of the intricacies of the humanitarian system, its actors and procedures, and have limited ability to reach and include the displaced populations in a meaningful way in their advocacy and programming efforts. DPOs generally lack long-term institutional support and strategic investments, such as those that support women's movement building efforts by financing grassroots women's groups and organizations around the world; leaving them in a precarious situation for more intentional and robust engagement in the humanitarian sector.

\section{Conclusions}

Millions of those displaced have one or multiple disabilities. They have lost their protective networks and often the few services that might have been available to them. The humanitarian actors, responsible for ensuring that people are assisted according to their needs, lack the awareness, capacity, and expertise to appropriately include persons with disabilities in their programs and services. This results in increased isolation, marginalization, and heightened risks-including of sexual and gender-based violence for refugee women and girls with disabilities. While expertise is available locally through organizations of persons with disabilities (DPOs), these organizations are seldom identified nor tapped. They are not brought into the humanitarian response as resources, service providers, or trainers.

The work outlined in this paper, highlights initial efforts by the Women's Refugee Commission to bridge the gap between DPOs and humanitarian organizations, to further capacitate and engage DPOs, especially organizations of women with disabilities, in humanitarian response, and to link displaced persons with disabilities to host country DPOs to reduce isolation, marginalization, and invisibility. The engagement of DPOs in humanitarian action could provide the needed expertise on disability inclusion that is so often lacking among humanitarian service providers and it could result in the strengthening of social networks for refugees with disabilities, ultimately enhancing their protection and inclusion.

Funding: This research received no external funding.

Conflicts of Interest: The author declares no conflict of interest. 


\section{References}

1. Women's Refugee Commission. Disabilities among Refugees and Conflict-Affected Populations. Available online: https://www.womensrefugeecommission.org/resources/document/609-disabilitiesamong-refugeesand-conflict-affected-populations (accessed on 29 October 2018).

2. UNHCR. Figures at a Glance. Available online: http://www.unhcr.org/en-us / figures-at-a-glance.html (accessed on 15 August 2018).

3. World Economic Forum. Available online: https://www.weforum.org/agenda/2017/06/there-are-nowmore-refugees-than-the-entire-population-of-the-uk/ (accessed on 4 October 2018).

4. UNHCR. Contribution to the Fifteenth Coordination Meeting on International Migration; Population Division Department of Economic and Social Affairs United Nations Secretariat: New York, NY, USA, 16-17 February 2017.

5. World Health Organization, World Report. Available online: http://www.who.int/disabilities/world report/2011/report/en/ (accessed on 15 August 2018).

6. Buscher, D.; Pearce, E. Bridging the Humanitarian-Disability Divide: From gaps to changes in policy and practice. In Crises, Conflict and Disability: Ensuring Equality; Mitchell, D., Karr, V., Eds.; Routledge: New York, NY, USA; London, UK, 2014; pp. 32-41, ISBN 978-0-415-81165.

7. Rohwerder, B. Intellectual Disabilities in Humanitarian Assistance Policy and Practice: The need to consider the diversity within disability, In Crises, Conflict and Disability: Ensuring Equality; Mitchell, D., Karr, V., Eds.; Routledge: New York, NY, USA; London, UK, 2014; pp. 168-174.

8. Women's Refugee Commission. Disability Inclusion: Translating Policy into Practice in Humanitarian Action. Available online: https://reliefweb.int/report/world/disability-inclusion-translating-policypractice-humanitarian-action (accessed on 29 October 2018).

9. Women's Refugee Commission and the International Rescue Committee. I See that It Is Possible: Building Capacity for Disability Inclusion in Gender-Based Violence Programming in Humanitarian Settings. Available online: https://www.womensrefugeecommission.org/resources/document/945-buildingcapacity-for-disability-inclusion-in-gender-based-violence-gbv-programming-in-humanitarian-settingsoverview (accessed on 29 October 2018).

10. Women's Refugee Commission. “Working to Improve Our Own Futures": Inclusion of Women and Girls with Disabilities in Humanitarian Action. Available online: https:/ /www.womensrefugeecommission.org/ disabilities/resources/1342-networks-women-disabilities (accessed on 29 October 2018).

11. Mosselman, M. Rhetoric vs. Reality: The Challenge of Delivering on World Humanitarian Summit Localization Commitments, Christian Aid, 2017. Available online: https://reliefweb.int/report/ world/rhetoric-vs-reality-challenges-delivering-world-humanitarian-summit-localisation (accessed on 16 August 2018).

12. Women's Refugee Commission. Mean Streets: Identifying and Responding to Urban Refugees' Risk of Gender-based Violence. Available online: https:/ /www.womensrefugeecommission.org/gbv / resources / 1272-mean-streets (accessed on 29 October 2018).

13. Women's Refugee Commission, AMDA Nepal, International Rescue Committee, Refugee Law Project, Sexual and Reproductive Health and Disability: Examining the Needs, Risks, and Capacities of Refugees with Disabilities in Kenya, Nepal, and Uganda, 2015. Available online: https:/ /www.womensrefugeecommission. org/images/zdocs / Reproductive-Health-and-Disability-Summary-Report.pdf (accessed on 4 October 2018).

14. Human Rights Council: Twentieth Session Annual Report of the United Nations High Commissioner for Human Rights-Thematic Study on the Issue of Violence against Women and Girls with Disabilities. 2012. Available online: https:/ /www.ohchr.org/EN/HRBodies/HRC/RegularSessions/Session20/Pages/ 20RegularSession.aspx. (accessed on 15 August 2018).

15. Ortoleva, S.; Lewis, H. Forgotten Sisters-A Report on Violence against Women with Disabilities: An Overview of Its Nature, Scope, Causes and Consequences. Northeast. Univ. Sch. Law Res. Pap. 2012, 104. Available online: https:/ / papers.ssrn.com/sol3/papers.cfm?abstract_id=2133332 (accessed on 4 September 2018).

16. Handicap International. Disability in Humanitarian Context-Views from Affected People and Field Organisations. Available online: https://reliefweb.int/report/world/disability-humanitarian-contextviews-affected-people-and-field-organisations (accessed on 29 October 2018). 
17. United Nations High Commissioner for Refugees. Action against Sexual and Gender-Based Violence: An Updated Strategy. Available online: https://reliefweb.int/report/world/sexual-and-gender-basedviolence-prevention-and-response-refugee-situations-middle-east (accessed on 29 October 2018).

18. United States Department of State. Implementation Plan for the National Action Plan on Women, Peace and Security. Available online: https:/ /www.pmc.gov.au/office-women/international-forums/australiannational-action-plan-women-peace-and-security-2012-2018 (accessed on 29 October 2018).

19. World Humanitarian Summit Secretariat. Restoring Humanity: Synthesis of the Consultation Process for the World Humanitarian Summit. Available online: https://www.eisf.eu/library/restoring-humanitysynthesis-of-the-consultation-process-for-the-world-humanitarian-summit/ (accessed on 29 October 2018).

20. Human Rights Watch. As If We Weren't Human: Discrimination and Violence against Women with Disabilities in Uganda. Available online: https:/ /www.hrw.org/report/2010/08/26/if-we-werent-human/ discrimination-and-violence-against-women-disabilities-northern (accessed on 29 October 2018).

21. Women's Refugee Commission. Building Networks among Refugees and Host Community Persons with Disabilities, Beirut, Lebanon. Available online: https:/ / www.womensrefugeecommission.org/populations / disabilities / research-and-resources / 1486-beirut-i-strengthening-peer-networks-for-refugees-withdisabilities (accessed on 21 August 2018).

22. Women's Refugee Commission. Strengthening the Role of Women with Disabilities in Humanitarian Action: A Facilitator's Guide. Available online: https:/ /www.womensrefugeecommission.org/populations / disabilities/research-and-resources/1443-humanitarian-facilitators-guide (accessed on 29 October 2018).

23. AWID and World Humanitarian Summit Advocacy Statements. Available online: https://www. womensrefugeecommission.org/disabilities/disability-strengthening-local-organizations. (accessed on 20 August 2018).

24. Humanitarian Disability Charter. Charter on Inclusion of Persons with Disabilities in Humanitarian Action. Available online: http:/ / humanitariandisabilitycharter.org/ (accessed on 27 August 2018).

25. United Nations-Disability. Optional Protocol to the Convention on the Rights of Persons with Disabilities. Available online: https://www.un.org/development/desa/disabilities/convention-on-the-rights-ofpersons-with-disabilities / optional-protocol-to-the-convention-on-the-rights-of-persons-with-disabilities. html (accessed on 27 August 2018).

(C) 2018 by the author. Licensee MDPI, Basel, Switzerland. This article is an open access article distributed under the terms and conditions of the Creative Commons Attribution (CC BY) license (http:/ / creativecommons.org/licenses/by/4.0/). 